\title{
Law as Authoritative Fiction
}

\section{Andrei Marmor}

There are several aspects of law that seem to be connected, but it is not entirely clear why and how. For one, law is an artifact, it is deliberately created by humans to serve some purposes. Furthermore, the law is created and modified by saying things; the law is one of those domains, like fiction, in which the saying so makes it so. But very much unlike fiction, law is an authoritative institution, and its authority is spaciotemporal, tied to location and relative to time. The main purpose of this essay is to show how various aspects of law and fiction are closely related, and how they exhibit features that are generally shared by expressive artifacts. Both law and fiction belong to a type of intangible artifacts, created by communicative means, giving rise to closed prefixed contexts in which truths in that context are constituted by performative speech acts. The law, however, is very much unlike fiction in that it is essentially authoritative. I conclude by showing how law's spacio-temporal aspect, which it does not share with most other expressive artifacts, derives from its authoritative nature.

\section{Law and fiction as closed prefixed contexts}

When we talk about the law we may be talking about very different things. In this essay I am interested in the law as normative content that can form a premise in a practical argument. Part of what we mean by the spacio-temporal aspect of law is that statements about any particular legal contents are necessarily prefixed by an implicit formula "According to the law in legal system $\mathrm{S}$ at time t...". So when you say, for example, that "Everyone who earns an income must file a tax return by April 18th", you must mean the complete proposition that "According to the Federal law in the USA (in force now, in 2017), all income earners have a legal obligation to file their tax returns by

\footnotetext{
${ }^{1}$ I do not intend to exclude various domains of international law from this generalization, though obviously the individuation of the relevant system may be a bit more complicated.
} 
April $18^{\text {st }}$." And this statement may be true, or not, depending on the relevant facts, some of them legal, others not. Now of course I am not assuming here that there is always a truth of the matter about statements formulated in this way. Legal content can be in doubt, sometimes it is genuinely indeterminate, or not yet determined.

Let us begin by focusing on the prefixing formula "According to the law in system $\mathrm{S}$ at time t..." or, which I take to be equivalent, "The law in $\mathrm{S}$ at t...". As I mentioned above, all statements referring to the content of the law on any particular issue must be prefixed by such a formula, which is to say that even if the statement is not expressed in this way, the prefix is at least implicitly presupposed. It makes no sense to state that positive law requires this or that without indexing it to some legal system or other at a given time; there are no free floating legal norms. ${ }^{2}$ Kelsen noticed this a long time ago, suggesting that norms can be legally valid only as part of a legal order, unified, Kelsen claimed, by derivation from a single basic norm. ${ }^{3}$ As Raz pointed out, Kelsen's assumption that legal systems are unified by derivation from a single basic norm is empirically questionable. ${ }^{4}$ But Raz understood and developed Kelsen's main insight here to mean that statements about the content of any given law can only made and articulated from the vantage point of some particular legal order. When I say, for example, that you have a legal obligation to $\varphi$ in context $\mathrm{C}$, what I must mean is that from the point of view of the relevant legal order, you ought to $\varphi$ in C. You may not have this obligation from a different normative vantage point, such as morality or religion, and you may not have this obligation in a different jurisdiction or according to a different legal system. Furthermore, as Raz famously argued, a speaker who asserts a legal proposition from the vantage point of a given legal order need not endorse that vantage point, normatively speaking; one can make "detached" statements about what the law in S requires or permits without

\footnotetext{
${ }^{2}$ I will come to qualify this statement later on, but not by much. Notice, however, that Natural Lawyers do not necessarily deny this; they hold that there is something they call Natural Law (and others call morality) that is universal and applies regardless of jurisdiction, but they would not conflate it with positive law. Natural Lawyers concede that positive law is jurisdiction-dependent. See, for example, J. Finnis, Natural Law \& Natural Rights ch 2.

${ }^{3}$ See, for example, H. Kelsen, General Theory of Law \& State, 42.

${ }^{4}$ J. Raz, The Authority of Law, ch 7.
} 
necessarily seeing oneself committed to the normative force of S. ${ }^{5}$ So this is, roughly, what I mean by the implicit formula of "According to the law in S at time t...".

Now the formula "According to $F$..." is prevalent in other contexts as well, and in itself, sometimes quite meaningless. We can say, for example, that "according to the laws of nature it is the case that X", but in this case, $X$ would be true, if it is, regardless of the prefix "according to F". The prefix here makes no difference to the truth value of the statement. But in the legal case it does. To see when and how the prefix "according to $F$ " (or "In $F$ ”) makes a logical difference, we should dwell for a moment on David Lewis's analysis of truth in fiction. ${ }^{6}$ Lewis starts with an example of how mixing different points of view in an argument may result in a fallacy. So here is Lewis's famous example:

Sherlock Holmes, we are told in the Arthur Conan Doyle mysteries, lived at 221B Baker Street in London. Let us assume, therefore, that there is some sense in which (1) is true:

(1) Sherlock Holmes lived at 221B Baker street, London

It turns out, however, that the building at 221B Baker street in London at the time was a bank. Let us therefore assume that at the relevant times, (2) is true:

(2) The building at 221B Baker street, London, is a bank.

The inference from (1) and (2) would seem to be:

(3) Sherlock Holmes lived in a bank

But of course (3) is clearly false. What has gone wrong here? Lewis tells us that we made the mistake of moving from a prefixed to an un-prefixed context. (1) is true only if it is prefixed by an operator such as "In the fiction $F$.."; whereas (2) is true only if taken as un-prefixed (in the real world, as it were). Thus, unless (2) is prefixed by the same operator "in fiction $F$...", you cannot conclude that (3) is true in the fiction; and because (1) is true only if it is prefixed, you cannot conclude that (3) is true in an un-prefixed sense. Surely, this is quite right, and I will refer to this problem as the Lewis fallacy.

\footnotetext{
${ }^{5}$ Raz, ibid. H.L.A. Hart disagreed with certain aspects of Raz's analysis, arguing that the relevant difference here pertains to different types of obligation; legal obligation is not like a moral obligation from a certain point of view. (Hart, Essays on Bentham, at 161). Yet of course Hart has never denied that legal obligations are indexed to particular legal orders, presupposing a particular legal point of view, as Kelsen and Raz have suggested.

${ }^{6}$ D. Lewis, "Truth in Fiction", at 262. See also A. Thomasson, Fiction and Metaphysics, at 107, and my The Language of Law, ch 3.
} 
Now, the Lewis fallacy requires some refinement, even in the case of fiction. Consider the following inference:

(4) Sherlock Holmes lived in London.

(5) London is a city in the United Kingdom

(6) Sherlock Holmes lived in the United Kingdom.

We have the same structure here as in (1) to (3), but a very different result. (4) is clearly prefixed by "In the fiction $F$....", whereas (5) seems to be un-prefixed, it is just a fact in the real world that London is in the UK. But there is no fallacy here. Any sensible reader of the Conan Doyle mysteries would have assumed, and rightly so, that Sherlock Holmes's escapades take place in the UK. ${ }^{7}$ And, crucially, this would be the case even if the United Kingdom (or England, or Great Britain) is never explicitly mentioned in the text. So what is it that makes the inference of (4) to (6) valid, as opposed to (1) to (3) which is not?

The solution has to be this: Although (5) seems to be an un-prefixed proposition, in the context of this inference it is not; (5) is incorporated into the fiction by implication. The assumption here is that fictions typically incorporate by implication an indefinite, though limited, number of facts (or factual assumptions) about the world, at least those that are relevant, and can be assumed to be salient and well known to potential readers. A reasonable reader of the Sherlock Holmes mysteries can be expected to know that London is a city in the UK, and thus, even if the text does not mention this explicitly, it can be regarded as incorporating it by implication. (Assuming, of course, that there is nothing in the text to suggest otherwise.) Thus we avoid the Lewis fallacy; the entire inference of (4) to (6) should be regarded as contained within the prefixed context. Similarly, even if the mysteries never refer to Sherlock Holmes's nose, we can assume

\footnotetext{
${ }^{7}$ To be sure, I am not suggesting that it is impossible to offer an interpretation of the Holmes stories according to which they take place in a parallel universe, where London is not in the UK. I am suggesting, however, that readers who assume that the Holmes mysteries take place in England would not be making any obvious mistake. And that's all we need for now. If you have doubts about the example, others can be thought of, e.g. that Sherlock Holmes had a nose, or a brain, etc.
} 
that he had one (and only one), in virtue of the stated fictional fact that he is a man. ${ }^{8}$ These kind of unmentioned facts can be said to be incorporated in the fiction by implication and thus, for inferential purposes, they can be regarded as prefixed statements.

The conditions and limits of implicitly incorporated assumptions in fiction are problematic, of course, and sometimes indeterminate. A nice example discussed in the literature concerns one of the Holmes stories, The Adventure of the Speckled Band, where the culprit is a snake, a Russell viper, that has climbed a rope to kill his victim. As it happens, however, the Russell viper is not a constrictor and cannot climb ropes. ${ }^{9}$ Is this a kind of fact that readers of Holmes mysteries are supposed to know? We're not even sure that Conan Doyle knew this. Would this necessarily matter to what is true in that fiction? Furthermore, it is plausible to assume that the extent to which unstated facts are incorporated in a fiction by implication is partly genre-dependent. Some fictional genres, such as realistic novels or detective stories, etc., are such that they tend to be rather generous with implicit incorporation of unstated facts, while other genres, such as surreal fiction, probably less so. We need not resolve these issues, suffice it to bear them in mind.

As we mentioned above, there are prefixes which create a Lewis-type fallacy, and others which don't. Let me call them closed and open prefixes, respectively. Open prefixes are such that they can occur in arguments with un-prefixed statements to yield valid conclusions. For example, prefixes such as "According to the laws of nature (or, according to science; or according to the laws of thermodynamics) ...."; or "According to modal logic...". So what is it about closed prefixes that they create the Lewis fallacy? One suggestion might be to look at the semantics of the prefix. It is probably implicit in the semantics of scientific prefixes that they range over un-prefixed statements to yield valid conclusions. In other words, it is probably part of what it means to prefix a statement by "according to science" that the statement following the prefix is meant to

\footnotetext{
${ }^{8}$ Notice, however, that fictional characters (and objects etc.,) have limited specifiablity; it may make sense to assume that Sherlock Holmes had some socks, but it makes no sense to wonder how many. In other words, no matter how detailed the description of a fictional character is, there will always be aspects of the character that remain unspecified, aspects that it makes not sense to try to work out in further detail.

${ }^{9}$ See, for example, A. Byrne, "Truth in Fiction: The Story Continued".
} 
apply unconditionally. ${ }^{10}$ Whereas it is part of the meaning of a prefix such as "according to fiction $F \ldots$.." that it ties the truth-value of the statement to be contained within a world demarcated by the prefix, that is, the world of fiction $F$. This is probably true, but it may not be enough. Still, you may wonder, what makes it the case that some prefixes are closed? The suggestion that I will endorse and try to support throughout this essay is that some prefixes are such that they designate a constitutive relation to the truth-values of the statements prefixed by them. A statement is true in a fiction, if it is, because the fiction states it. The saying so makes it true, so to speak. It doesn't mean that there are no limits here; even fiction cannot make it the case that $\mathrm{X}$ is true in the fiction if $\mathrm{X}$ is something that we cannot possibly imagine or otherwise entertain in your minds (such as a "square circle" or even, perhaps, "a delightful torture of an innocent child".) What those limits are and how to account for them is an interesting question, but we need not try to resolve it here. $^{11}$

In short, closed prefixes are those in which a constitutive relation obtains between certain essential features of the world/context designated by the prefix, and the truths of the statements expressed in that world/context. Now you might wonder what other prefixes are closed, besides fiction, that is? Law, I will argue shortly, is a closed prefix; but there are many others. Structured games, for example, constitute closed prefixed contexts. When the umpire in a soccer game orders a player "out", it is true, in the game of soccer, that the player has to leave the field. The game is a closed prefixed context. It is only according to the rules and conventions of the game that if the umpire orders the player "out", then the player, in the game, from the game's perspective, as it were, is to leave. The rules and conventions of the game constitute the context that determines certain statements about that context to be true or false. ${ }^{12}$

\footnotetext{
${ }^{10}$ Not necessarily, of course; pragmatics is always relevant. In some contexts of conversation or in some populations, "according to science" may be used to express what the speaker takes to be a closed prefix. Consider, for example, someone from a fundamentalist evangelical community saying, "Well, according to science it is the case that X....". Such a speaker may mean quite the opposite of what we mean, suggesting that $\mathrm{X}$ is not really true, it's only true from a "scientific" perspective, one the speaker does not quite share, as it were.

${ }^{11}$ See, for example, Nils-Hennes Stear, "Imaginative and Ficntionality Failure: A Normative Approach".

${ }^{12}$ See my Social Conventions, 59-61. Of course not all statements about things that happen in a game are prefix-dependent. We can say, for example, that " $A$ ran to catch the ball", which is true or false regardless of the game context.
} 
Sometimes the question of whether a prefix is closed or not is in the eye of the beholder, as it were. The prefix "According to the Bible..." is a case in point. Consider, for example, the biblical story of the Flood, whereby God eliminated all humans from the earth, with the sole exception of Noah and his family. In the late $15^{\text {th }}$ century, when Europeans discovered humans inhabiting the Americas, they faced a quandary with the Flood story: had the indigenous people of the Americas been spared the flood or not? Either way, difficult questions loomed. If the Flood has not reached the Americas, why was it not mentioned in the Bible? If, on the other hand, the indigenous Americans are also decedents of Noah, how did they get over the oceans to settle in that far away land? Of course this is a quandary only for those who regard the prefix "According to the Bible...." as an open prefix. If, on the other hand, you regard the Biblical prefix closed, like myth or fiction, then you would see that the quandary of the Flood story, like so many others in that vein, is just an instance of the Lewis fallacy.

Why is the law, however, a closed prefix? A good starting point is to see that the truth value of any statement about the content of a legal premise depends on the specific jurisdictional prefix. Take any statement expressing some legal premise, such as (7) "A ought (legally) to $\varphi$ in C", and you will immediately realize that whether (7) is true or false depends on the specific prefix. According to the law in $S_{1}$ at $t,(7)$ can be true, and according to the law in $S_{2}$ at $t$ it may not be. (And the same goes for the time variant. It may have been true until last week but no longer is.) Some legal philosophers may doubt that this is necessarily the case. Perhaps there are some universal truths about legal contents that are not prefix variant. What I have in mind here are very general principles, such as the idea that wrongs need to be rectified, criminals need to be punished, or agreements need to be kept, and things like that. There is a sense in which it might be true that all legal systems must instantiate some such principles, and therefore there might be a sense in which such abstract and general precepts are universally legal, as it were, unprefixed. I doubt that there is a serious sense in which such principles are legal, but it doesn't matter much for our purposes. After all, actual laws can deviate from such principles; not all wrongs are legally rectified and not all promises are binding contracts, etc. So there might be some general principles that law purports, perhaps even 
necessarily, to instantiate; but it is the instantiation that legally matters, not the guiding ideals.

Be this as it may, suffice it for our purposes if you agree that, by and large, the truth value of legal statements is prefix dependent. But still, you might think that this is not enough to make the legal context a closed prefix. After all, we don't seem to get the Lewis fallacy by mixing legal statements with un-prefixed statements of non-legal facts. On the contrary: almost every legal syllogism seems to do just that, reach a legal conclusion from statements about the law and statements about non-legal facts. Consider this example:

(8). According to the law in $\mathrm{S}$ at $\mathrm{t}$, anyone who is an $\mathrm{X}$ ought to $\varphi$ in circumstances $\mathrm{C}$.

(9). John is an $\mathrm{X}$ (in S at t)

(10). Therefore, John ought, legally, to $\varphi$ in C.

Clearly (8) is a prefixed statement and it would seem that (9) is not, it is just a fact in the world, so to speak, that John happens to have feature $\mathrm{X}$ in the relevant time and circumstances. And yet, despite the fact that we seem to mix a prefixed premise (8) with an un-prefixed premise (9), we get a valid conclusion in (10). But this is an illusion. The legal conclusion in (10) follows only if (9) is incorporated into the legal prefix by implication, presupposition, or stipulation. It has to be the case that according to the law in $\mathrm{S}$ at $\mathrm{t}$, John is an X. Factual premises must be incorporated, explicitly or implicitly, into the legal framework to make legal syllogisms valid. ${ }^{13}$

Consider a simple case. Suppose it is the law (here and now) that accepting an offer under specified conditions amounts to the formation of a legally valid contract. Suppose you offer to sell me your car for a certain amount of money, and I reply by saying "Yes, I accept the offer". May we conclude that we just formed a legally valid contract? Not so fast: It depends on whether our relevant expressions in the particular context count as an offer and an acceptance in the eyes of the law; there has to be an explicit or implicit legal finding that they do. And notice that these kind of findings can always be legally challenged and debated. Events in the world need to be internalized

${ }^{13}$ See also my The Language of Law, 81-84. 
into a legal framework, they need to be legally recognized as relevant or established facts, to form premises in legal arguments. Without such incorporation to the prefixed context, we do get the Lewis fallacy.

Lawyers often talk about something similar but in a way that is potentially confusing. Lawyers acknowledge the "finding of fact(s)" as an essential aspect of any legal argument, but the expression is ambiguous. In one sense it can mean exactly what I suggest here, that the relevant facts need to be incorporated in to the legal framework; but in another, perhaps more common sense, it can simply mean the authoritative ascertainment of what really happened. In litigation contexts, therefore, the finding of facts is a two stage affair: courts may need to ascertain what really happened, whether A really said that $X$ or whether $B$ really intended to kill his victim, things like that; and then when the event in the world has been found, authoritatively, to have occurred, there is a finding, as it were, though often implicit, that the way things happened counts as the legally incorporated fact or event. It may be worth keeping in mind that, quite generally, the assumptions about what counts as a legally relevant fact inevitably guides the findings of fact in the factual sense. After all, events and actions in the world allow for an indefinite number of descriptions and levels of specification. Which ones we pick out to ascertain for purposes of formulating premises in a legal arguments depends on what counts, legally speaking, as the relevant kind of fact. Therefore, when we include a factual assumption in a legal argument, that is, when we rely on a certain non-legal fact as a premise in the argument, we thereby implicitly incorporate it into the legal prefix. By stating that this fact matters, legally, we make that fact, as it were, part of the legal framework, we implicitly assume that it is the kind of fact that counts, legally, as the relevant kind.

To put this in a formal way, any legal syllogism involving premises about legal content and non-legal facts, must conform to this form:

(1) According to the law in $\mathrm{S}$ at t, If $\mathrm{X}$ then legal result $\mathrm{Y}$

(2) $E_{x}$ [an event in the world of $X$ type]

(3) $\mathrm{E}_{\mathrm{x}}$ legally counts as $\mathrm{X}$ in $\mathrm{S}$ at $\mathrm{t}$.

(4) Therefore according to S at t, X 
(5) Therefore [legal result] $\mathrm{Y}$ in $\mathrm{S}$ at $\mathrm{t}$.

Unlike in fiction, however, it would seem that there are no antecedent conditions attached to the kinds of facts law can incorporate into its prefixed context. In the fictional context we would think that factual assumptions can be incorporated within a given fictional story only under certain conditions, such as common knowledge of the relevant facts, relative salience, relevance to the story, lack of contrary indication in the text, etc. In the legal case, however, it seems that there is no room for such constraints; in principle, any non-legal fact or event in the world can be incorporated into the legal context if the law applies to it. And the law can apply to almost anything. Now this, I think, is true but only up to a point or, to be more precise, with an important caveat. The law does not necessarily incorporate into its prefixed context every true factual assumption that follows, logically and empirically, from facts it relies upon, explicitly or implicitly. In other words, non-legal facts are not automatically incorporated into the legal context even if they are true and potentially relevant; incorporation of facts to the prefixed world of a legal context often requires authoritative finding, and sometimes the actual authoritative finding defies empirical truth, and even logical consistency.

Suppose, for example, that the law in $\mathrm{S}$ at $\mathrm{t}$ is (11) “ Anyone in possession of an object with feature X ought to $\varphi$ in context Z".

Now suppose that people would normally assume that objects of type A, B, and C are objects with feature $\mathrm{X}$; so they would assume that in context $\mathrm{Z}$, anyone who possesses $\mathrm{A}$, $\mathrm{B}$, or $\mathrm{C}$ ought to $\varphi$, according to this law. But now suppose it also happens to be the case, though not widely known, that objects of type $\mathrm{D}$, perhaps not sharing any conspicuous features with objects of type A, B and C, also happen to have feature X. Does (11) apply to objects of type $\mathrm{D}$ as well? The legal answer is not obvious, and cases in which a court might decide otherwise are not unheard of. A nice case in point is Nix v Hedden ${ }^{14}$ where the Court held that tomatoes are to be classified as vegetables and not fruit for the purposes of the tariff regulation in question, even though, as the court acknowledged,

${ }^{14} 149$ U.S. 304 (1893). 
tomatoes are, actually, fruit. Or Yates $v U . S .^{15}$, where the Court decided that fishes are not "tangible objects" for the purposes of the Federal law in question. True factual assumptions are not necessarily incorporated into the law, even when they are clearly relevant. And the same goes for logical consistency; the law often tolerates, and sometimes for good reasons, a certain level of incoherence. ${ }^{16}$

\section{Saying so makes it true that so}

At least part of what explains the fact that law, like fiction, is a closed prefixed context stems from the fact that in both cases, of law and of fiction, the domain is one of those in which the saying so makes it so. John Searle remarked once that you cannot fry an egg just by saying that "I hereby fry an egg", but if you are a minister you can marry a couple by saying that "I hereby declare you husband and wife"; and anyone can make a promise by saying "I hereby promise you to $\varphi$ ". ${ }^{17}$ Speech act theorists have called these examples performative speech acts, whereby by uttering an expression the speaker can accomplish a certain action beyond the act of stating or affirming a proposition. But the category of performative speech acts is very wide, and there are good reasons to think that there are several different kinds of performatives. ${ }^{18}$

Some speech acts gain their performative aspect in virtue of rules or conventions at the background which stipulate that A's saying " $\mathrm{S}$ " counts as doing $\mathrm{Y}$ in context $\mathrm{C}$. The rules constituting the legality of marriage, for example, stipulate that a minister's declaration, in the appropriate circumstances, counts as marrying a couple. Or the rules of an institution may stipulate that the chair of a committee can officially adjourn a meeting by declaring that the meeting is adjourned. In such cases the saying so makes it so only because rules or conventions make it the case that the saying so counts as doing a certain kind of act. Elsewhere I called this type of cases institutional performatives. ${ }^{19}$ Other

${ }^{15} 674$ U.S. (2015)

${ }^{16}$ See my "The Rule of Law and its Limits".

${ }^{17}$ J Searle, "How Performatives Work".

${ }^{18}$ I am partly relying here on more detailed arguments I presented in my Social Conventions, ch 5.

${ }^{19}$ Both J Austin and J Searle have held the view that this is how all performatives work, they all necessarily rely on some rules or conventions in the background. For a more detailed account of the debate between Austin and Searle on the one side, and Strawson and Bach \& Harnish on the other side, see my Social Conventions, ch 5 . 
types of performatives, however, perhaps most, actually, may not require any rules or conventions to enable the performative aspect of the speech act. As Strawson demonstrated a long time ago, one can perform an act of warning simply by saying, under appropriate circumstances, "The ice over there is very thin!" ${ }^{20}$ In saying this one performs an action, beyond that of asserting a proposition, of course, by way of expressing an intention that the hearer can grasp as the intention it is, namely, of warning you that the ice is thin and you'd better be careful. According to Bach and Harnish, most performatives operate in this way because most of them express a statement about the attitude of the speaker, and the performative succeeds as such when the hearer recognizes the relevant attitude or intention expressed. ${ }^{21}$ Let me call these types of cases general performatives. Finally, there are performatives which are not statements at all, they are not truth-apt expressions, but count as actions of certain types by way of making recognizable moves in a conventional practice, such as greeting or thanking and such. I called them conventional performatives, because these are the kind of expressions that gain their literal meaning as recognizable moves in some conventional social practice or other. $^{22}$

In short, there are several types of performatives and their felicity conditions might be quite different. However, the types of cases in which the saying so makes it so that I'm interested in here is closely related, but different. I want to focus on cases in which the saying that " $\mathrm{S}$ " in a given context makes it the case that $\mathrm{S}$ is true in that context. Now, there is a considerable overlap between performative speech acts and cases in which a statement is rendered true by its expression alone. ${ }^{23}$ By saying to your friend that she is invited to your dinner party, for example, you make it true that she is now invited to the party, and this is true only because you have expressed the invitation. Similarly, by expressing a promise to someone you have made it true that you promise,

\footnotetext{
${ }^{20}$ P Strawson, "Intention and Convention in Speech Acts"

${ }^{21} \mathrm{~K}$ Bach \& R Harnish, Linguistic Communication and Speech Acts, \& their reply to Searle "How Performatives Really Work".

${ }^{22}$ Social Conventions at 127-129.

${ }^{23}$ On sentences rendered true by their expression alone, see Lemmon, E. J., "On Sentences Verifiable by their Use". According to Bach \& Harnish ("How Performatives Really Work"), all performatives are such that their expression, under appropriate circumstances, renders them true, because they are all expressions of the speaker's attitude. Elsewhere I raised some doubts about this generalization; at the very least, their analysis cannot be applied to conventional performatives where the expression is not truth-apt. see Social Conventions ch 5 .
} 
and you made it true by virtue of saying so. And if you tell your employee, for example, that he is fired, then you make it true that the employee is fired, and it's true by virtue of your saying so. ${ }^{24}$ In short, there are countless performatives that express a statement which is rendered true by its expression alone, under the appropriate conditions, of course.

Now consider truth in fiction. Generally speaking, something is true in a given fiction because the fictional text says so. If a fictional text says that "the moon is green" then it is true, in that fiction, that the moon is green, and it's true because the fiction says so. (Unless, of course, the fiction also says something else that would make you doubt that it really asserts that the moon is green.) As we noted above, the saying need not be explicit; some content can be incorporated into a fiction by implication. But even incorporated content is a function of saying so; content incorporated into a fiction has to follow from, or be presupposed by, what the fiction says.

Let's take a step back: There is no fictional story unless the story has been told by someone. Even a myth or a legend has had to be told by someone at some point; sentences in some natural language have to be expressed, whether written down or voiced. Fiction is an artifact, it has to be created by humans. And it is an artifact created by saying things. ${ }^{25}$ Let me call these cases expressive artifacts, that is, artifacts created by sayings or, more generally, by use of expressive means of symbolism or communication. To paraphrase Searle again, though you cannot create a chair by saying "I hereby make a chair", you can create a story by simply telling it. Generally speaking, intangible artifacts, like fiction, poetry, music, myths, religion, etc., are created by means of communication, they are constituted by sayings. Intangible artifacts, quite generally, tend to be expressive artifacts, constituted by means of expression.

There is a complex web of connections here so let me recap briefly. The starting point is to bear in mind that there are countless types of action we can perform by a speech act, beyond the act of asserting a proposition. Some of these actions are made

\footnotetext{
${ }^{24}$ I use examples in which the sentence expressed employs an explicit performative verb, such as "promise", "fired", "adjourned", etc.,. Most of these performatives can be accomplished without using the explicit performative verb. Also notice, however, that an unambiguous sentence can use a performative verb literally without it being used as a performative. (I can tell Sarah, for example, that I am promising John something or, that I am firing Jim, but by this I have not used the performative terms to perform anything.)

${ }^{25}$ See A. Thomasson, Fiction and Metaphysics, ch 3.
} 
possible by rules or conventions in the background which stipulate that saying " $\mathrm{S}$ " in context $\mathrm{C}$ counts as doing $\mathrm{Y}$ in that context. Other performative speech acts do not rely on any particular conventions or rules in the background (that is, beyond the rules and conventions of the relevant language, of course). Most performative speech acts also exhibit the feature that something is rendered true by saying it. It is often the case that a statement $\mathrm{S}$ is rendered true by uttering $\mathrm{S}$ in the normal, appropriate, circumstances. Finally, and most importantly for our purposes, there are expressive intangible artifacts created by performative speech acts. Expressive artifacts belong to domains in which the saying so makes it true that so in the relevant domain. Both law and fiction, I will argue, are expressive artifacts in this sense. And I will argue that expressive artifacts, at least those in which truth-aptness applies to some degree ${ }^{26}$, are closely tied to the idea of closed prefixed contexts.

\section{Law as Expressive Artifact}

Before we proceed with the argument, there are few things I need to say about the nature of artifacts. An artifact is an object created by humans for some purpose. There are many kinds of artifact in the world we inhabit. There are chairs, cars, computers, houses, and countless other objects deliberately created to serve some function or purpose in our lives. We can use them for their intended purpose or for other purposes, perhaps not intended; we can modify their uses in various ways. It is generally thought that artifacts are objects deliberately created for some purpose, with that purpose in somebody's mind, as it were. And that is surely correct about most ordinary artifacts we use in our daily lives. But deliberate creation for a purpose is not necessary for an artifact to come into existence as such. Some artifacts may have been created by chance, or later significantly modified by repeated use, without any deliberate design. What is essential for an object to be an artifact, I will assume here, is that it has been created by humans and that it is used by humans for some typical or designated purpose or other.

\footnotetext{
${ }^{26}$ I do not mean to claim that in all the familiar forms of expressive artifacts truth-aptness applies. Perhaps there are no truths in music, for example, though music is undoubtedly an expressive artifact. And there may be others in which a truth operator has no role to play. Notably, some philosophers doubt that truth plays any role in fiction; K Walton's pretense theory of fiction, in Mimesis as Make-Believe, is a case in point. But $c f$ Thomasson Fiction and Metaphysics, 97.
} 
Not all artifacts are objects in the physical sense. Many of the artifacts we have are intangible: Novels, poems, legends, gods and, generally, narratives, would be prime examples. ${ }^{27}$ Stories are created by human beings. They have authors, even if, sometimes, the authors are not known and difficult to individualize (as with the coming into existence of a legend or a myth). What makes stories artifacts is the fact that they are created by humans, with their particular properties or content, if you will. I hope we can proceed by assuming that the intentions with which an object is created are not necessarily constitutive of what that object is. We can certainly grant that artifacts, tangible and intangible, come into existence intentionally. They are intentionally created as objects of a certain kind. But it is not always the intention of the original creator of an object that makes it an artifact of a certain kind. Something that was created or otherwise came about as an $\mathrm{X}$, may become a $\mathrm{Y}$-artifact by repeated and widespread $\mathrm{Y}$-uses of it. Creation is sometimes no more than recurrent and widespread intentional use. ${ }^{28}$

Generally speaking, though exceptions are possible, artifacts exist, and persist, when there is a population or a community that treats them as such. ${ }^{29}$ Chairs are the kind of artifacts they are because we use them for something, to sit on, mostly. Imagine a world in which there are chair-shaped objects, but nobody uses them (nor ever has used them) for sitting on or, let us assume, for anything at all. They are just there, scattered around. In that world there are no chairs, only chair-like objects. And the same goes for intangible artifacts. A song is an anthem when it's used as such by a certain population, a legend is the kind of fiction it is when a population treats (or has treated) it in certain

\footnotetext{
${ }^{27}$ Sometimes the distinction between the tangible and the intangible is a difficult one to draw. Cinema, and some of the performing arts, like theater, opera, dance, etc, convey contents in ways that are very similar to ordinary fiction, but they also have a tangible aspect that fiction lacks, they require some spacio-temporal performance or instantiation. For our purposes in this paper, however, we can regard at least cinema, theater and opera along the same lines we regard fiction.

${ }^{28}$ A nice example is the incorporation of traditional African masks to the Western art world in the early decades of the $20^{\text {th }}$ century. African masks were not originally created as works of art, at least not as the concept of art has been understood in the West. But once influential artists in Europe started to regard African masks artistically, and started exhibiting them as such, they have become works of art, that is, regardless of the actual intentions and purposes of those who created them. Things like this happen not infrequently. (I am aware of the fact that I hereby contradict something I wrote many years ago, about this particular example, embarrassingly. See my Interpretation and Legal Theory, 82-83.)

${ }^{29}$ Can there not be single-use artifacts? It is certainly possible for someone to invent a contraption for a particular purpose, then use it perhaps for this or that purpose, without any larger community involved in the process. But then we would not have a concept for that thing, it would be an ad hoc tool, not an artifact.
} 
ways, and fiction, quite generally, is enabled by our practice of engaging in imaginative cognition, suspending belief in the truth of what we are invited to envisage or imagine.

Many of the artifacts we encounter are compound, by which I mean that they are artifacts within artifacts. Think about a painting or a sculpture exhibited in an art museum. The painting is an artifact, of course, but so is the museum. Thus a painting exhibited in a museum is an artifact within an artifact, but not only in a spacial sense. An art museum is an institution with certain features created by humans for certain purposes, serving various functions. When a painting is exhibited in a museum, the exhibition, in the context of a museum, gives the painting certain meaning and function that it might not otherwise have. In some cases, the differences are subtle, in others, quite profound. A Rembrandt painting might not be affected all that much by being exhibited in the Frick collection; but the exhibit of a mirror stuck in a pile of sand in an art gallery may contribute to the artistic nature of the object a great deal. ${ }^{30}$ It may not even be a work of art without the institutional support it gets by being positioned where it is. Putting an artifact in another artifactual context often changes the quality of the artifact. ${ }^{31}$ And this is not something that is confined to tangible artifacts, like objects of art. Sometimes it's a mix of the tangible with the intangible; a computer program is an intangible artifact that operates on a tangible one. Printed books and more generally, writing, convey contents, as intangible artifacts, by physical means, means that are themselves artifacts. So I hope you can see that there are many kinds of compound artifacts.

There is a particular kind of compound artifact, however, that is relevant to both fiction and law. There are many instances in which social conventions shape the ways of creating artifacts of a certain kind. There are conventions, for example, about what counts as a realistic novel, or as epic poetry, and those conventions would shape and guide ways in which authors create a novel or write an epic poem and of course, the ways in which we read them. There are conventions about symbolism that would shape the ways in which directions in space are indicated, and thus signs made, etc. In previous work I

\footnotetext{
${ }^{30}$ I am not inventing this example. Robert Smithson's "Leaning Mirror" (1969), currently exhibited in Dia Beacon NY, is exactly that, a double sided mirror stuck in a pile of sand.

${ }^{31}$ Here is another similar example: consider the difference between exhibiting an object in an art museum and exhibiting it in an anthropology museum. The same object is likely to be seen in different light depending on the kind of museum in which it is exhibited. Which, is of course, why political controversies often surround decisions where and how to exhibit various cultural artifacts.
} 
argued that there are conventions about what counts as a competitive game, and they would shape ways in which we invent and play structured competitive games, how we react to them, etc. ${ }^{32}$ If conventions are also artifacts, as I think they are, then these would all be examples of compound artifacts. A novel, for example, would instantiate both original creation by the author, which would make it a paradigmatic example of an intangible artifact, but also some conventional norms and guidance in the background, contributing something, perhaps tacitly, to what the novel as an artifact is. And this makes, essentially, every novel a compound artifact. Novels, in this respect, are very much like paintings in an art museum, obviously in a more intangible manner.

I am assuming that there is not much I need to say by way of establishing that conventions are (intangible) artifacts. Conventions meet all the conditions about artifacts we mentioned above; they are created by humans for particular purposes, their persistence and contents depend on the ways in which they are actually used, and metaphysically speaking, their existence is a function of what users make of them. ${ }^{33}$ Now it is true, of course, that conventions are rarely created in a deliberate manner to serve as conventions; conventions tend to emerge in an organic, often slow and invisible manner, evolving in ways that are difficult to retrace with any great accuracy, even in retrospect. But as I mentioned before, this is often true about artifacts, even tangible ones.

I hope we said enough here to show that law, like fiction, and perhaps art in general, is a compound artifact. But let's take the analogies a step further, or rather, back to the point we started with, to see how law and fiction are created by expressive means. They are both compound expressive artifacts. And that is so, because in both cases, as in some others, the saying so makes it so. Fiction is created by telling a story, that is, by expressing sentences in a natural language. And notice that the story told is constitutive of the truths in it. And so is the law. Law is created by performative speech acts, mostly of the institutional kind. And those speech acts constitute what the law is, they constitute what is true in the law. There are limits to this, of course; just as there are ways in which

\footnotetext{
${ }^{32}$ See my Social Conventions, 59-61.

${ }^{33}$ This is not meant to be a general statement about the ontology of artifacts. In the metaphysical debates about the ontological status of artifacts I try to stay above the fray. Thomasson (Fiction and Metaphysics) rightly explains, I think, that the ontological debates should focus on the question of how to understand metaphysical dependence relations and the principle of parsimony. Cf P. van Inwagen, Material Beings, ch 13. I have no views on these issues.
} 
one can fail to tell a story, say, by asking us to envisage the unimaginable, authorities can fail to make law in various ways. ${ }^{34}$ Furthermore, I do not mean to exclude the possibility that there may be other things that contribute to legal contents, even moral considerations, if you insist. But that is true of fiction as well; many things can contribute to ways in which we interpret a fiction, besides what the fiction says or implicates. In both cases, however, the story has to have been told by someone for there to be a story that we can think of and interpret in various ways.

Law is created in myriad ways at different levels. Legal rights, obligations and powers can be created, modified and abolished at individual levels, at group levels and generally, at the level that applies across an entire jurisdiction. In all these cases, the creation or modification of the law is done by speech acts. In previous work I argued, at some length, that the enactment of a law, by democratic institutions or otherwise, is a collective speech act, and I will not repeat the argument here. ${ }^{35}$ We can add to it, however, by noticing the multitude ways in which institutional performative speech acts modify the law. Judicial decisions can create or modify the law by the court's holding that the law is this or that; Contractual obligations are formed by speech acts, that is, by one making an offer and the other accepting it; official acts with legal ramifications are carried out by regulations and instructions, and so on and so forth. All over the spectrum we create and modify the law by performative speech acts. And most of these performative speech acts, including enactment of laws, are of the institutional kind; there are rules or conventions in the background stipulating that A's saying " $\mathrm{S}$ " in context $\mathrm{C}$ counts as doing Y. Which is, of course, what makes the law a compound artifact, and a rather complex one at that.

One possible exception that comes to mind here is customary law. It is sometimes the case, perhaps more so in the international domain, that laws are created, as it were, by long standing custom, that is, by some general and consistent conformity with a presumed norm over a long period of time. Now the question of how to reconcile

\footnotetext{
${ }^{34}$ Famously, traditional Natural Law has been understood to claim that an attempt to legislate that which is profoundly unjust or immoral is a failure to make law. Very few people still hold such a view, but there are other, more plausible cases in which one can fail to make law. Perhaps if the relevant saying is so confused as to make it utterly unclear what is said, one made no law; perhaps if the directive requires people do that which cannot be done the directive is failed law. These are all complicated and controversial issues. On some of these issues I have dwelt in my "The Rule of Law and its Limits".

${ }^{35}$ See my The Language of Law, ch 1
} 
customary law with the idea that laws have to be created in some deliberate manner, is an old chestnut. My purpose here is not to defend any particular version of good old legal positivism. Suffice it to see that law is very much like fiction in this respect as well. Most fiction is created by an author deliberately telling a story, in writing or by some other expressive means. But we have quite a lot of fiction stemming from myths and legends, the origins of which are often obscure and intractable. As I mentioned above, artifacts, quite generally, often come into existence in obscure ways, and what determines their existence as an artifact of a certain kind is mostly a matter of repeated widespread use for some purpose or other. And that is true of expressive artifacts as well. They must have been created by some speech acts at some point, but their original creation sometimes matters little to ways in which we use them now, and ways in which we understand their contents.

You may still press the question of whether customary law is an exception to the idea that law is generally created and modified by performative speech acts. I may not have a clear answer to that, but it doesn't matter much. Even if there are some exceptions, the law is created, by and large, by speech acts. And the kind of speech acts in question are typically institutional performatives, namely, enabled by rules or conventions at the background determining that by saying " $\mathrm{S}$ " in context $\mathrm{C}$, one performs $\mathrm{Y}$, that is, one creates or modifies something that is legally significant. Generally speaking, however, in the legal context, very much like in fiction, the saying so makes it so, it makes it true, in the context, that it is the law.

Law, like fiction, is an expressive artifact, and that has a lot to do with the fact that both are closed prefixed contexts. Like fiction, the law does not describe how things are, irrespective of its own creation, as it were; it creates a world in itself by stipulating that the relevant legal world is so and so. And this, I hope you can see, is what makes the legal domain a closed prefix. If the law purported to describe how things are in the world outside it, then of course it would be an open prefix; but the law is not in the business of telling us how things are. It is in the business of telling us how they ought to be, or what we ought to do, from a legal point of view. And in actual legal systems, those who make the law make it true, in the law, that it is what they say it is, because law, like fiction and 
like other expressive artifacts, is one of those domains in which the saying so makes it so. ${ }^{36}$ And hence it is a closed prefix.

Now of course the creation of law is much more complex than fiction; as I mentioned earlier, in every jurisdiction there are countless people and institutions who can contribute to what the law is on this or that, from legislatures and courts, to administrative agencies, bureaucrats, corporations, and even private individuals in their everyday transactions. But these complexities do not change the essential picture. All these creations and modifications of law are performative speech acts given their legal significance by a complex web of rules and conventions (many of which are themselves previously enacted legal rules).

Generally speaking, then, I submit that expressive artifacts are closed prefixes; enacting a law gets you only as far as enacting a law, something that is true in a particular legal order, and only from a legal point of view. Stories and laws, by themselves, don't make anything true outside the story or the legal world, so to speak. Now of course a good story is one that you can learn something from, and it should reveal to you truths or insights of various kinds beyond it. And that is true of law as well. There is a lot we can learn from the law, about the human condition and human relations, about morality and politics and whatnot. But you don't learn these things by way of accepting their truths in virtue of the law's saying so. What is true in a fictional story is one thing, what you can learn from it is another. Similarly, what is true in the law or, what the law is, is one thing, and what you can learn from it is another.

Furthermore, we should keep in mind that both with respect to fiction and law, as with respect to other closed prefixed contexts, statements can be made from the vantage point of the prefixed context as well as externally, about things in that context. Not everything we say about a fiction has to be said from the point of view of the fiction in question; we can express statements about it, externally, as it were. A great deal of literary theory and literary discourse is external, in this sense. ${ }^{37}$ It makes statements about various aspects of the prefixed context, but from the outside, as it were. For example,

\footnotetext{
${ }^{36}$ The general view that law is something that has to be created by deliberate human action (not uncontroversial, I'm aware,) is a view I have defended in detail in the past; see for example, my Philosophy of Law, chs 1-4.

${ }^{37}$ See Thomasson, Fiction and Metaphysics, at 105-6.
} 
saying that "Sherlock Holmes is a detective" is an internal statement, rendered true or false by what the story says or implicates. But saying that "The character of Sherlock Holmes exhibits stereotypes of chauvinism typical of Victorian England" is not prefixed.

It is a statement about certain aspects of the prefixed context, not within it. And of course the same goes for statements about the law. When we say that the law requires this or that, we would normally make the statement as prefixed by the relevant legal order; but we can also make many statements about aspects or elements of the legal order that are external, not prefixed. Which is essentially what we do, for example, when we subject laws to moral scrutiny or other kinds of critique. ${ }^{38}$

\section{Law's Spacio-Temporal Aspect}

In one conspicuous sense, however, the law is very much unlike fiction and most other expressive artifacts: it is authoritative. ${ }^{39}$ And it is authority backed by force, closely tied to actual political sovereignty. It is precisely because the law is authoritative that the legal prefix is jurisdictional. Practical authorities, in general - whether backed by force or not -- are authorities only relative to their jurisdiction. Jurisdiction is something that defines the scope of an authority's normative powers, answering the question of what are the issues on which an authority gets to decide and with respect to whom (and both are relative to a time frame, of course). There is no practical authority without some jurisdictional boundaries. Now, this is not the place to develop a theory of practical authority to substantiate these claims, I have done that elsewhere. ${ }^{40}$ But I need to recap some of the main points I made in developing an institutional conception of authority to help us see the relevant connections here. The main argument is that the answer the question of what it is to have a practical authority is a three-stage affair: To have practical authority is to have normative power in some systematic sense; power, in this systemic sense, must be granted or constituted by norms, that is, some rules or conventions; and

\footnotetext{
${ }^{38}$ Though the distinction I mention here may sound very similar to H.L.A. Hart's distinction between internal and external points of view (The Concept of Law, ch 5), it is really not the same. As I explained elsewhere, Hart's distinction pertains to the possibility of a reductive explanation in the context of legal normativity, not about prefixed as opposed to un-prefixed statements. See my Philosophy of Law, at 53-55.

${ }^{39}$ Keep in mind, however, that many religions have authoritative elements imbedded as well, which is one of the main differences between religions and myths.

${ }^{40}$ See my "An Institutional Conception of Authority".
} 
such power-conferring norms are essentially institutional, that is, they form part of some institution or social practice. Notice that these three conditions only pertain to what it is to have authority. They do not bear directly on any question of moral legitimacy or moral reasons to comply with any putative authority's directives.

Normative power is not necessarily systematic in the sense in which authorities have power. For example, it is plausible to maintain that consent, quite generally, is an exercise of normative power. It enables a person, unilaterally, to change the normative situation that had obtained prior to the consent. For example, people have an obligation not to touch me; by consenting to being touched by someone in a given context, I waive this obligation in that particular context. So this is an exercise of normative power we all have by virtue of moral reasons, regardless of any particular social background, presumably. ${ }^{41}$ Practical authorities, however, have much more complex normative powers. To be a practical authority is to have powers to choose from a range of options whether and how to introduce changes in the normative landscape that prevails in the area of one's authority, and this kind of power is complex: it typically includes choices about how to introduce a change, who is subject to it, how to monitor non-compliance and how to respond to it, how to modify the directives if need arises, etc., etc.,. In other words, authoritative powers are inevitably complex, constituted by a set of interlocking norms, defining who gets to have the power, the content and scope of the power, ways in which it can be exercised, ways in which it can be enforced, and other auxiliary matters. And these kinds of things can only be constituted by rules or conventions.

In previous work I argued that the only kind of rules or norms that can confer these kinds of powers on authorities are social or institutional rules. Practical authorities must operate within some social practice or an institution that grants them the kind of normative powers they have. ${ }^{42}$ However, even if you doubt that this is necessarily the case, I hope you would see it as unproblematic to concede that the de facto authority of law is entirely practice dependent, at least in this limited sense. Namely, in the sense that there is no legal authority without it forming part of a complex social practice in which it operates and which grants it the normative powers that it has. And I hope we can also see

\footnotetext{
${ }^{41}$ In various contexts there may be conventional ways of expressing consent, but that does not make consent as exercise of power depend on conventions.

${ }^{42}$ See my "An Institutional Conception of Authority", 246-7.
} 
that it is precisely this practice dependence of authorities that grounds the idea of jurisdiction. Authorities can only obligate those who belong to the practice or institution that grants them the powers they have. Whether legitimate or not, Canadian law can only apply to those subject to Canadian jurisdiction, it cannot obligate US residents, for example. Similarly, the dean of Harvard Law School cannot give me work related instructions unless I work there, and I don't. So he or she have no jurisdiction over me, no matter how wise or sensible their academic directives are. Practical authorities' normative powers are always limited to the particular jurisdiction in which they have those powers. $^{43}$

Necessarily one can only have jurisdiction at any given time relative to some population. Authoritative powers are always relative to those who are subject to the normative powers in question, which is to say, confined to the people who participate, voluntarily or not, in the social practice that grants the authority the powers it has. ${ }^{44}$ But in the legal case, normative powers meet brute power; legal authority is the kind of authority that is backed by force, brute force, I mean, and that tends to make legal authority territorial. The exercise of brute power over people, especially on larger scale and over some extended period of time, tends to be very closely associated with control over territory. Which is to say that legal jurisdiction is, practically speaking, almost invariably territorial. And indeed, territorial boundaries are often quite vivid. By crossing a line, literally speaking, that is, you can cross to a different legal regime, sometimes dramatically different. And the temporal aspect of laws is just as vivid: not only particular directives, but an entire legal regime that has been in force for a while may cease to apply at a given moment, as when a major piece of legislation is introduced or repealed or, more dramatically, when a whole legal regime is replaced by revolution.

I don't think that I made any philosophical news here. Nor would it be surprising to hear that none of this territorial stuff applies to other expressive artifacts, like fiction. Fiction has nothing to do with practical authority, and it certainly has nothing to do with

\footnotetext{
${ }^{43}$ Legal systems sometimes try to extend their authority to populations beyond their jurisdiction, as in cases in which laws of one country purport to apply to people or institutions in other countries; unless backed by international law, these extra-territorial laws tend to have no legal impact, at least not extra-territorially.

${ }^{44}$ As I explained elsewhere in some detail ("An Institutional Conception of Authority", 248-252), the question of whether participation is voluntary or not, and to what extent, has a crucial bearing on the conditions of the legitimacy of practical authorities.
} 
brute force. Fiction has no jurisdictional aspects. But other intangible artifacts do have some jurisdictional elements. Structured competitive games tend to have clearly demarcated jurisdictions, they have boundaries. The boundaries typically demarcate terms of participation, they draw the line between participants and observers, and things like that. And then, of course, many religions have jurisdictional elements, partly because they purport to be authoritative, and partly due to legalistic or quasi-legalistic aspects of the religion. In short, I don't think that the jurisdictional aspect of law is all that unique to it, other expressive artifacts may exhibit similar aspects. What is unique to law, however, as an expressive artifact that purports to exercise practical authority over people, is its close connection to, or even dependence on, brute force. Law is the kind of expressive artifact, maybe the only kind, that is forced on us by brute power. Law and political sovereignty are difficult to separate. And this makes the law not just authoritative fiction, it makes it fiction backed by force. A strange thing this is, but the law is a strange kind of artifact and, in some respects, rather unique. ${ }^{45}$

\footnotetext{
${ }^{45}$ I am grateful to the reviewers of the journal for very helpful comments.
} 


\section{REFERENCES}

K Bach \& R Harnish, Linguistic Communication and Speech Acts (MIT Press, 1979)

--- "How Performatives Really Work" 15 Linguistics and Philosophy, (1992), 93.

A. Byrne, "Truth in Fiction: The Story Continued" 71 Australian Journal of Philosophy (1993), 25

J. Finnis, Natural Law \& Natural Rights, (Oxford, 1980).

H.L.A. Hart, The Concept of Law (Oxford, 1961, $2^{\text {nd }}$ ed., 1994).

--- Essays on Bentham (Oxford, 1982)

H. Kelsen, General Theory of Law \& State (Wedberg trans., Russell \& Russell, NY 1961)

Lemmon, E. J., "On Sentences Verifiable by their Use” 22 Analysis, (1962) 86.

D. Lewis, "Truth in Fiction”, Philosophical Papers Vol. 1, (Oxford, 1983), 261.

A. Marmor, The Language of Law (Oxford, 2014)

--- Philosophy of Law (Princeton, 2011)

--- Social Conventions (Princeton, 2009)

--- Interpretation and Legal Theory (Revised $2^{\text {nd }}$ ed, Hart Publishing, 2005)

--- “An Institutional Conception of Authority", 39(3) Philosophy \& Public Affairs, (2011), 274.

--- "The Rule of Law and its Limits", 23 Law \& Philosophy, (2004), 1.

N-H. Stear, "Imaginative and Ficntionality Failure: A Normative Approach", 15

Philosopher's Imprint, (2015).

J. Raz, The Authority of Law (Oxford, 1979)

J. Searle, "How Performatives Work", 12 Linguistics and Philosophy (1989), 535.

P. Strawson, "Intention and Convention in Speech Acts", Logico-Linguistics Papers, (Methuen, London, 1971), 170. 
A. Thomasson, Fiction and Metaphysics (Cambridge, 1999)

P. van Inwagen, Material Beings (Cornell U Press, 1990)

K. Walton, Mimesis as Make-Believe (Harvard U Press, 1990) 